\title{
Modelling of Rock Cutting with Asymmetrical Disc Tool Using Discrete-Element Method (DEM)
}

\author{
Grzegorz Stopka ${ }^{1} \mathbb{C}$
}

Received: 8 October 2020 / Accepted: 6 August 2021 / Published online: 21 August 2021

(c) The Author(s) 2021

\begin{abstract}
The use of asymmetrical disc tools for the mining of hard and very hard rocks is a promising direction for developing mechanical mining methods. A significant obstacle in developing mining methods with the use of asymmetric disc tools is the lack of adequate computational methods. A deep understanding of rock-tool interaction can develop industrial applications of asymmetric disc tools significantly. The fundamental problem in designing work systems with asymmetric disc tools is the lack of adequate analytical models to identify tool loads during the mining process. One reasonable approach is to use computer simulation. The purpose of the research was to develop a simulation model of rock cutting using an asymmetrical disc tool and then evaluate the developed model. In the article, the Discrete-Element Method (DEM) in LS-Dyna was adopted to simulate rock cutting with asymmetrical disc tools. Numerical tests were conducted by pushing the disc into a rock sample at a given distance from the sample edge until the material was detached entirely. Two types of rock samples were used in the simulation tests: concrete and sandstone. The independent variables in the study were the disc diameter and the cut spacing. To validate the simulation model, analogous laboratory tests were carried out. The article presents a comparison of the results of simulation and laboratory tests. The given comparison showed good accordance LS-Dyna model with the experimental studies. The proposed test results can be input data for developing simulation models on a larger scale. Thus, it will be possible to consider the complex kinematics of the dynamics of the rock-mining process with disc tools using the DEM simulation.
\end{abstract}

Keywords Disc tools $\cdot$ Discrete-element method (DEM) $\cdot$ Simulation $\cdot$ LS-Dyna $\cdot$ Hard rock mining

\section{Introduction}

One of the most interesting directions in hard rock mining is related to the use of asymmetric disc cutters in mechanical excavation systems. Two basic techniques of mechanical rock mining can be distinguished by means of disc tools, namely excavation with static pressure and undercutting (Fig. 1). The use of disc tools allows, compared to the standard mining method, to reduce the energy consumption of the mining process and leads to the reduction of dust generation associated with mining. Due to the significant reduction of friction forces in the rock-mining process, the abrasion wear of cutting tools is also increasing. However, the undercutting

Grzegorz Stopka

stopka@agh.edu.pl

1 Department of Machinery Engineering and Transport Machines, AGH University of Science and Technology, al. Mickiewicza 30, 30-059 Kraków, Poland method provides the theoretical benefit of reducing mining forces compared to mining with conventional symmetrical disc tools. Since this cutting action generates tensile stresses in the rock much more directly than the conventional technique, it is far more efficient, meaning that the force required to break the rock is much lower (Ramezanzadeh et al. 2010). The above advantages of using disc tools resulted that over the past decades, many attempts of industrial application of asymmetric disc tools have been undertaken. Disc tools were used in the simple and complex kinematics of the working system (Weber 1995; Jeong et al. 2019). Attempts are made to apply disc tools not only on conceptual (prototype) machines but also in industrial ones that have used the standard mining tools (picks, teeth) (Asbury et al. 1998; Gospodarczyk et al. 2013; Acaroglu et al. 2017).

Modelling and research in applying asymmetrical disc tools in mechanical excavation systems are one of the primary research directions implemented at the Department of Machinery Engineering and Transport at AGH UST in 

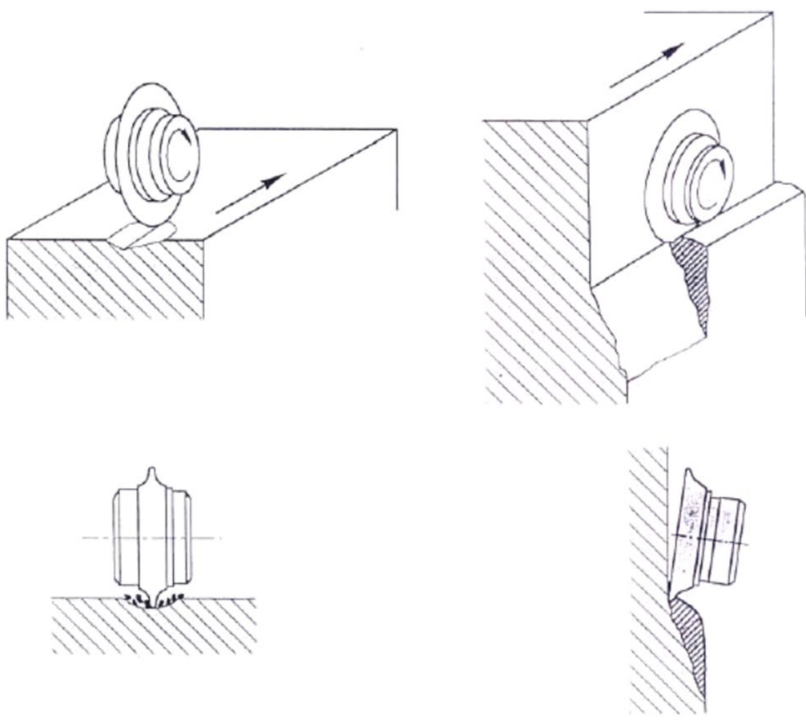

Fig. 1 Conventional disc cutting (left) and undercutting (right) (Ramezanzadeh et al. 2010)

Krakow, Poland (Bołoz 2018; Gospodarczyk et al. 2016; Kotwica 2018). An example of this type of work is developing and implementing a new generation of disc head dedicated for use in the construction of roadheaders. The disc head concept assumes the mining of rock stone by chipping as a result of a complex trajectory of disc tools. It is presented in Fig. 2. The elaborated mining unit consists of an independently propelled body and mounted in it propelled discs with asymmetrical disc tools. Unit body 1 is propelled by an external drive shaft 2 . In the body, in seats 3 drive shafts 6 are mounted with plates 4 , on which in bearing seats 10 disc tools 5 are installed. The most favourable number of the tools should be $6-8$ pieces. The drive shafts 6 are propelled by an internal drive shaft 7 independent from the external drive shaft 2 and a set of bevel gears 8 and 9 or alternative ones. The mining head's presented design with disc tools has been successfully verified in series of field tests. The field tests showed correct kinematics of the mining process. In the conclusions of the tests, it was emphasised that a roadheader using a mining head with disc tools needed only about $60 \%$ of the power compared to a conventional mining head.

However, this type of innovative application of asymmetric disc tools requires the use of proven calculation procedures to verify the reliability of such new mining system's solutions. The reason for this is the complex process of rock destruction during rock cutting by disc tools. The essence of destroying the cohesion of rocks by disc tool in a simplified way can be illustrated using the example of the wedge profile's penetration into rock half-space. A characteristic feature of this process is the relatively small size of the socalled compression zone. Therefore, the foremost part of the excavated material during the disc mining is the volume of side fragments. The course of penetration of the wedge profile into a half-space is characterised by dynamic variability, which directly affects the pressing force's value during mining. The consequence of this fact is the difficulty of formulating a full mathematical description of the process of disc's blade penetration into the rock body. In connection with the above, models specifying the mining resistance forces assume simplifications and allow only for an approximate estimation of forces acting on the tool during rock excavation. It should be emphasised that the computational models of different authors are most often the result of their experimental research. Therefore, they are valid in the area of restrictions that were considered during the experiment. The analytical formulas for describing the resistance forces of disc mining assume simple kinematics of the mining system (most often rectilinear). The use of analytical formulas for calculating disc tool loads is often insufficient. It is possible to generate errors when defining boundary conditions for new and innovative types of mining machinery (Stopka 2019, 2020).

The fundamental problem in the design of work systems with asymmetric disc tools is the lack of adequate analytical
Fig. 2 Conception of a unit equipped with asymmetric disc tools of a complex motion trajectory (left) and the prototype (right)
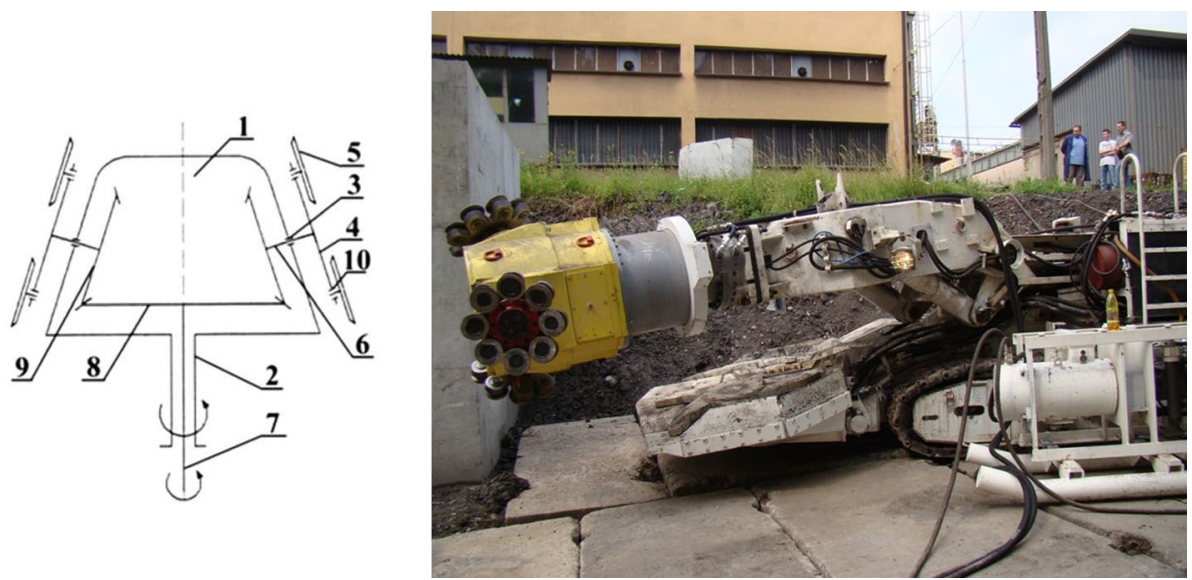
models to identify tool loads during the mining process. One reasonable approach is to use computer simulation. However, simulation of the process of rock destruction by tool impact is a complex problem. Regardless of the choice of a numerical method, simulation of a process with such complex characteristics involves the need to identify many parameters of material and contact models. An additional problem is the long computation time and the associated model accuracy. The characteristics of simulation models are not universal but change with the characteristics of the mining process and the geometry of a tool. Previous experience of the research team from the Department of Mechanical Engineering and Transport of the AGH University of Science and Technology in Cracow from design works and tests of the new generation disc head pointed to a big problem in the scope of modelling mining with asymmetrical disc tools. This applies especially to the optimization of numerical models in terms of calculation time and accuracy.

Taking the above into consideration, the DEM model of asymmetric disc-rock interaction was developed as a part of the research being the subject of this paper. The aim of model tests was to demonstrate the adequacy of applied model with respect to laboratory tests, assuming certain numerical parameters of the DEM model, which significantly affect the computation time (linear model of the particle-particle contact, maximisation of the DEM particle radius).

In view of the objective adopted, it was assumed that the tests would be carried out assuming simple mining kinematics with an asymmetric disc tool. Therefore, the tests consisted of simulating the pressing of an asymmetrical disc into a rock sample. This approach allowed for the evaluation of approximate loads on the disc head, and at the same time, ensured that the models could be validated on a laboratory bench with sufficiently high accuracy of tool positioning relative to the sample. The independent variables in the study were: disc diameter $(D=150$ and $160 \mathrm{~mm})$, mining pitch $(t=15-25 \mathrm{~mm})$, mechanical properties of rock samples (concrete, sandstone). To evaluate the accuracy of developed DEM models, the maximum destruction force and the size of the destruction zone were calculated for each test, and the measured parameters were compared with the results of laboratory tests.

\section{General Approach to Rock Cutting Modelling}

Nowadays, computer technology development provides the capability of rock-cutting simulation using various modelling techniques, such as the Discrete-Element Method (DEM) or Finite-Element Method (FEM). To extend the possibilities of modelling the rock-tool interaction, it is also possible to combine both numerical methods (FEM-DEM) (Zárate at el. 2015).

The Finite-Element Method (FEM) is one of the numerical methods that can analyse complex engineering problems. Due to a large number of material models and failure criteria, the FEM can be used to modelling rock-tool interaction (Li et al. 2012a, b). The basic approach to modelling rock cutting in FEM is based on using the Mohr-Coulomb failure criteria or similar models. The most advanced approach in rock-cutting modelling in FEM is related to the use of the Concrete Damage model, Johnson Holmquist Concrete model, or the Continuous Surface Cap model (CSCM) implemented in LS-Dyna software (Jaime et al. 2015). The use of the above models in the FEM allows simulation of rock's cracks and fragmentation.

The second numerical method that can be used to simulate rock cutting is the DEM. The discrete-element method (DEM) is a particle-based numerical method that can model a system's mechanical behaviour composed of an assembly of discrete spherical particles. The method models part composed of rigid spheres that can move independently and interact with one another. According to numerous studies, the DEM provides a better understanding of the mechanical behaviour of rocks and rock masses. It has been proven as an efficient and economical method to give a useful insight into rock fragmentation and fracture formation under complex load conditions (Zhang. et al. 2020). During the past decade, numerical simulations of rock cutting with the use of the DEM have been carried out by many researchers. The largest research group was research focussed on simulation rock cutting with conical picks (Rojek at el. 2011; Qianqian at el. 2015; Zhang at el. 2020). The DEM has also been used to simulate rock cutting by disc tool, especially for disc tools used in full-face tunnel boring machines (TBM). Researchers conducted DEM simulations of rock cutting subjected to symmetrical disc tools to study the rock fragmentation and its relation to applied cutting force (Rojek 2007; Li et al. 2012b, Li and Du 2016, Labra at el. 2017, Xia at el. 2017).

However, there is no comprehensive modelling and laboratory research in the literature on asymmetrical disc tools. Therefore, due to the development of the new generation of disc head, it was decided to develop simulation DEM models that would allow identifying loads of a single asymmetrical disc tool. The purpose of the research was also to validate the model and its optimization due to the time of calculations. The discrete-element method (DEM) in LS-DYNA was employed to investigate the disc tool-rock interaction. The implementation of the DEM in the LS-Dyna program has been used many times in research on the dynamic behaviour of materials (Karajan at el. 2012; Flores-Johnson at el. 2016; Takeda at el. 2018). 


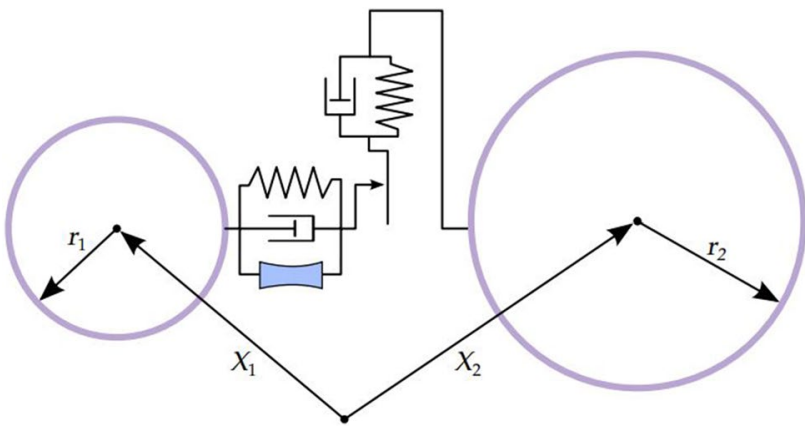

Fig. 3 Schematic representation of sphere-sphere interaction

\section{Numerical Model of Rock Cutting by Asymmetrical Disc Tool}

\subsection{Discrete-Element Method in LS-Dyna}

The DEM implemented in LS-DYNA is based on the method first developed by Cundall and Strack (Cundall and Strack 1979; Hallquist 2015). As usual for the DEM, a penaltybased contact is used to capture the particle-particle and particle-surface interaction. Figure 3 shows a schematic contact interaction between two particles. This elastic contact model is defined with normal and tangential stiffness, damping coefficients, static and rolling friction coefficients.

Normal contact force is calculated as the following equations:

$F_{n}=K_{n} d_{i n t}$

where

$d_{i n t}=r_{1}+r_{2}+\left|X_{1}-X_{2}\right|$.

Parameter $d_{i n t}$ defined the interaction distance with $X_{i}$ dentoing the coordinates of the ith particle. The normal spring constant $K_{n}$ is defined as follows:

$K_{n}=\frac{k_{1} r_{1} k_{1} r_{1}}{k_{1} r_{1}+k_{1} r_{1}} N O R M K$,

where $k_{i}$ and $r_{i}$ are the compression moduli and radii of the $\mathrm{i}$ th particle, respectively, and NORMK is a user-specified stiffness penalty parameter. The parameter $k_{i}=E_{i} / 3\left(1-2 v_{i}\right)$ is in LS-DYNA form the user-specified particle's Young's modulus E and the Poisson's ration $v$ (Karajan et al. 2012). The tangential spring constant is given by

$K_{s}=K_{n}$ SHEARK,

where the default value of the stiffness parameter SHEARK is $2 / 7$ (Karajan et al. 2012). The normal damping force is defined as follows:
$F_{\text {ndamp }}=D_{n} \dot{d_{\text {int }}}$,

where the damping constant $D_{n}$ is given by

$D_{n}=2 N D A M P \sqrt{\frac{m_{1} m_{2}}{m_{1}+m_{2}} K_{n}}$.

NDAMP is the normal damping parameter $(0 \leq N D A M P \leq 1)$. The tangential damping force is defined in a similar way as Eq. (4) with TDAMP and $K_{t}$ being used instead of NDAMP and $K_{n}$, respectively.

The DEM method in LS-Dyna can also be used to model brittle material fracture by bonding the loose DEM particles. To simulate brittle material fracture, the parallel bond method (PBM) for DEM particles was implemented in LSDyna. The essence of the method is shown in Fig. 4

In this method, all particles are linked to their neighbouring particles through bonds. The properties of the bonds represent the complete mechanical behaviour of solid mechanics. Bonds can be broken under excessive load, which allows us to simulate the initiation and propagation of material fracture. The properties of the bonds (DE BOND) are adjusted by assigning normal (PBN) and shear stiffness (PBS) and maximum normal (PBN_S) and maximum shear stress (PBS_S) for bond rupture. The maximum gap between two particles that are meant to be bonded can be prescribed via the parameter MAXGAP. This gap is either a multiple of the smallest radius of the two spheres, i.e. MAXGAP $\times \min \left(r_{1}\right.$, $r_{2}$ ), or an absolute value for the gap, depending on MAXGAP being greater or smaller than zero, respectively. Due to the DEM is a fully dynamic formulation, damping is necessary to dissipate kinetic energy. In LS-Dyna bond model, the numerical damping coefficient (ALPHA) is used to calculate the damping force between particles that formed the bond. In LS-Dyna, it can be any value between 0 and 1 .

Where $\mathrm{r}_{1}$ and $\mathrm{r}_{2}$ are the radii of bonded spheres, $\Delta \mathrm{F}_{s}$ and $\Delta \mathrm{F}_{\mathrm{n}}$ are, respectively, shear and normal force increments applied within each time increment of the analysis.

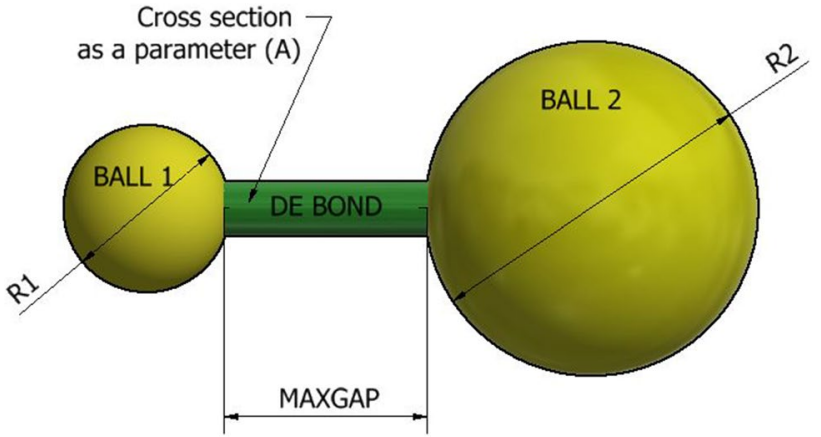

Fig. 4 Basic parameters of bonded particles in LS-Dyna 
The normal force between two bonded discrete elements with radii $r_{1}$ and $r_{2}$ is calculated as follows:

$\Delta F_{n}=\frac{P B N}{\left(r_{1}+r_{2}\right)} A \Delta u_{n}$,

where

$A=\pi r_{e f f}^{2}$

$r_{\text {eff }}=\min \left(r_{1}, r_{2}\right) S F A$.

The shear force is calculated as follows:

$\Delta F_{s}=P B S \frac{P B N}{\left(r_{1}+r_{2}\right)} A \Delta u_{s}$.

The moments are calculated as follows:

$\Delta M_{n}=\operatorname{PBSJ} \Delta \theta_{n}$

$\Delta M_{s}=P B N I \Delta \theta_{s}$,

where

$J=\frac{\pi}{2} r_{e f f}^{4}$

$I=\frac{\pi}{4} r_{e f f}^{4}$

SFA is a radius multiplier scaling the bond circular cross-section area by multiplying the minimum radius amongst the two involved radii from two bonded spheres. By adjusting the bond radius multiplier, it is possible to bond each particle to several other particles.

Fracture in the material will be initialised by bonds breaking, where only a few broken bonds can be seen as a micro-crack and when several more bonds are breaking the evolution of a macro-crack (Ten at el. 2013). Strength PBN_S and PBS_S are the strength components of the bond, respectively, for normal and shear direction. Normal direction is the direction parallel to the bond cylinder axis, and the Shear direction is perpendicular to that in all orientations. The maximum normal and shear stress acting on the parallel bond are formulated as follows:

$\sigma_{\max }=\frac{-F_{n}}{A}+\frac{\left|M_{s}\right| r_{\text {eff }}}{I}$

$\tau_{\max }=\frac{\left|F_{s}\right|}{A}+\frac{\left|M_{n}\right| r_{e f f}}{J}$.

If the maximum normal stress exceed the normal strength $\left(\sigma_{\max } \geq P B N \_S\right)$ or the maximum shear stress exceeds the sher strength $\left(\tau_{\max } \geq P B S \_S\right)$, the parallel bond breaks.

\subsection{Calibration of Material Models}

The main assumption for the research was to use at least the modelling of two types of rock samples. Therefore, computer simulation of rock cutting by asymmetrical disc tools was carried out on concrete and sandstone samples. In the first step, laboratory tests for determining rock sample's strength (UCS and BTS tests) were conducted. The test results are presented in Table 1. As it is widely known, establishing numerical and physical parameters of the DEM model is complex and cannot be derived from the laboratory experiments directly. Therefore, the material's macroand micro-parameters must be calibrated by simulating the rock mechanical experiments. Numerical modelling in this investigation was mainly conducted by the use of DEM in LS-Dyna software. The micro- and macro-parameters are calibrated by simulating both the UCS and BTS tests. Therefore, simulation tests were carried out for individual types of samples. Figure 5 illustrates the cylindrical model of concrete sample for the simulation of the UCS and BTS tests.

The basic independent variables in calibration tests were: radius of particles (RDES), the maximum gap between particles (MAXGAP), bond cross-section (A), particle stiffness parameters $\left(\mathrm{K}_{\mathrm{n}}, \mathrm{K}_{\mathrm{s}}\right)$, and bond stiffness parameters (PBN, PBS, PBN_S, PBS_S). In the first stage, the uniaxial compression of rock samples was simulated. In the case of the correct representation of the sample's elastic properties and the maximum destructive force, in the next step, the verification of the DEM model in the BTS tensile test was conducted. In the case of a negative result in the BTS test (inadequate parameters of the sample's stiffness or the destructive force), the base parameters were modified, and the UCS and BTA tests were repeatedly verified. After the testing stage aimed at verifying the DEM model in the USC and BTS tests, a control test with a disc tool was carried out at a mining pitch of $t=15$ (short calculation time). Achieving an acceptable error $\left( \pm 2 \mathrm{R}_{\mathrm{DES}}\right)$, in this case, meaning that the disc tool tests could be continued for the remaining set of parameters (different values of disc diameter and cutting pitch). The procedure was repeated until obtaining a positive result in both strength tests. The calibration scheme is presented in Fig. 6.

Table 1 Mechanical properties of rock samples

\begin{tabular}{lll}
\hline Parameter & Concrete & Sandstone \\
\hline Density, kg/m & 2130 & 2450 \\
Uniaxial compressive strength (UCS), MPa & 23.7 & 78.8 \\
Brazilian tensile strength (BTS), MPa & 2.3 & 5.7 \\
Young's modulus, GPa & 1.6 & 9.2 \\
Poisson's ratio [-] & 0.275 & 0.21 \\
\hline
\end{tabular}


Fig. 5 LS-Dyna model for the simulation of UCS (left) and BTS (right) test
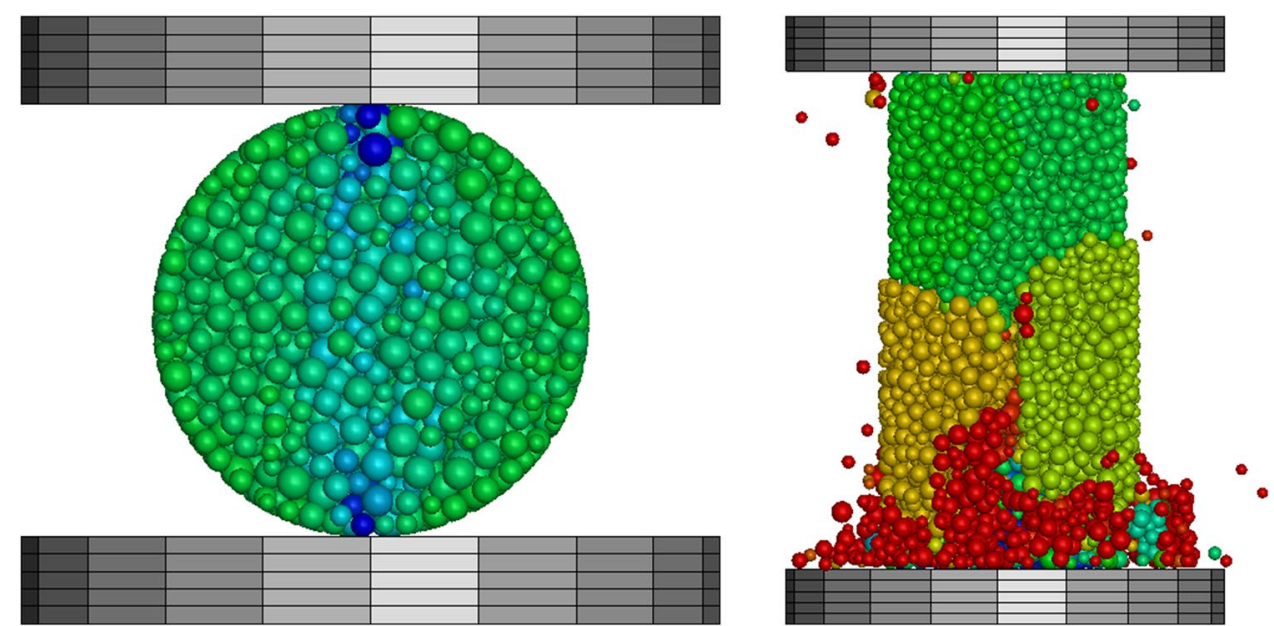

Figures 7 and 8 illustrate force-displacement relationship obtained in laboratory tests of the unconfined compression (UCS) and Brazilian tests (BTS) for concrete. These curves allowed to determine the micro-macro-properties of the material model with the discrete-element method. An important assumption was to determine the size of the particles that on the one hand, will guarantee the accuracy of calculations, and on the other hand, will not generate long simulation time for full-scale tests with disc tools. In the following figures plotted, green curve are the results of simulation tests for calibrated models. The same calibration procedure was conducted for sandstone. The calibration results for both materials are summarised in Table 2.

\subsection{Testing Methodology}

Simulations of rock cutting by asymmetrical disc tools have been performed using the model shown in Fig. 9. Numerical tests were conducted by pushing the disc into a rock sample at a given distance from the sample edge until the material was detached entirely. Based on the literature analysis of the subject as well as the previous author experiences in the field of industrial application of disc tools, it has been determined that the tests will be carried out changing geometric and process parameters, such as:

- diameter of the disc tool $D=150$ and $160 \mathrm{~mm}$.

- cut spacing $t=15,20$ and $25 \mathrm{~mm}$.

- mechanical properties of the rock sample (concrete, sandstone)

During simulation tests, the disc tools of blade angle $40^{\circ}$ and tip radius $R=1 \mathrm{~mm}$ have been considered. Based on previous laboratory tests, the dimensions of the rock sample were determined. Observation of the mechanism of rock destruction during mining tests with asymmetrical disc tools allowed to establish the required dimensions of the rock model, that is illustrated in Fig. 9.

Simulations of the mining process with asymmetrical disc tools have been carried out using LS-Dyna software. The virtual $3 \mathrm{D}$ model of disc tools and rock samples has been discretised in the next step. The disc tool has been discretised with over 188.000 triangular elements, considering a refinement in the disc tip to reproduce its curvature (Fig. 10). The disc tool was treated as a rigid body with a prescribed translational motion perpendicular to the rock sample. To define the disc tool movement, a constant velocity was imposed. The constant velocity was equal to $0.03 \mathrm{~m} / \mathrm{s}$ for concrete samples and $0.01 \mathrm{~m} / \mathrm{s}$ for sandstone samples. These parameters were established based on the basis of pilot disc mining tests. Characterisation of the particle assembly for the test with disc tools is presented in Table 3.

The results of model discretization in LS-Dyna DEM code are shown in Fig. 10. The DEM particles were set in contact with the disc with the use of the contact Node to Surface Contact. The static and dynamic friction coefficient was set to 0.3. During simulation tests, displacement of the backside and right side of the sample was fixed (marked in Fig. 11), whereas the other sides were set to free.

\section{Results of Simulation}

Exemplary results of simulation tests of rock cutting by asymmetric disc tool are shown in Figs. 12, 13, 14 and15. The calculations were conducted on an HP Z840 workstation $(2 \times$ Intel Xeon 2650). In the case of concrete tests for $t=15 \mathrm{~mm}$, the calculation time was about 3-4 h. For sandstone and $t=20 \mathrm{~mm}$, the calculation time was about $65-70 \mathrm{~h}$. The following figures illustrate material failure induced by the pushing disc cutter into a rock sample. It is illustrated with the damage parameter defined as the ratio of the number of broken bonds to the initial number of cohesive bonds 
Fig. 6 Calibration scheme of DEM model

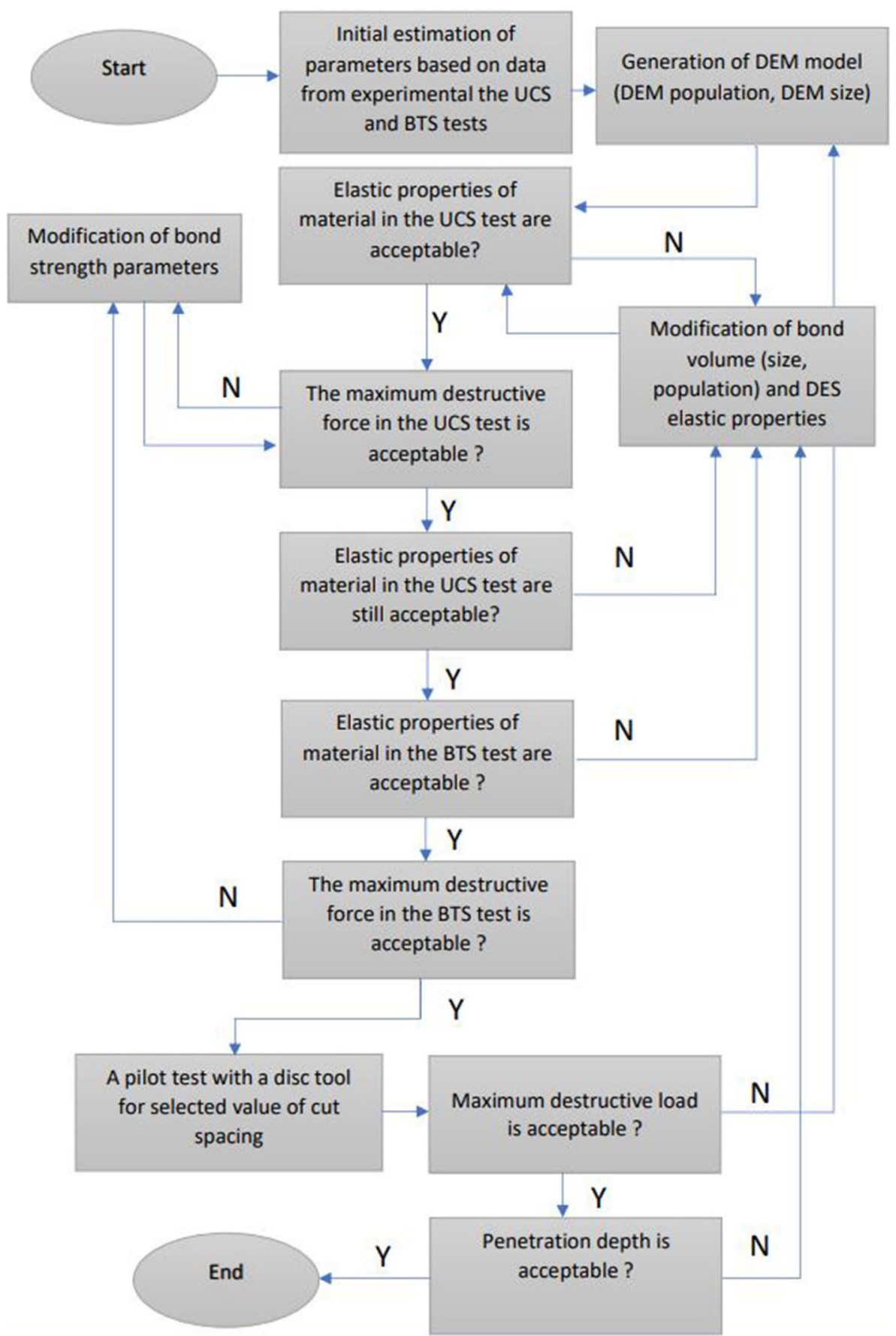

for each particle. The value of the damage parameter ranges from 0 to 1 . It is equal to 0 for the undamaged material and 1 for the completely damaged one. Observations of the process of rock destruction in simulation tests, especially the shape of the destruction zone, allow identifying many similarities to laboratory test results. All the tests were completed by chip separation, whose dimensions (height, depth) were multiple times higher of the assumed cut spacing. The volume of rock fragments after the mining process with a disc tool was dependent on the value of cut spacing and mechanical properties of samples. A higher volume of rock fragments was observed for sandstone samples. Depending on the configuration of the geometric parameters tested and the properties of the sample, the disc penetration causing the sample to be destroyed ranged from 5 to $10 \mathrm{~mm}$. This parameter was consistent with the results of analogous laboratory tests (Stopka 2020).

During simulation tests normal (press) force $\left(\mathrm{F}_{\mathrm{z}}\right)$ and lateral force $\left(\mathrm{F}_{\mathrm{x}}\right)$ acting on a disc tool were monitored. These parameters were the most critical factors that were used to 


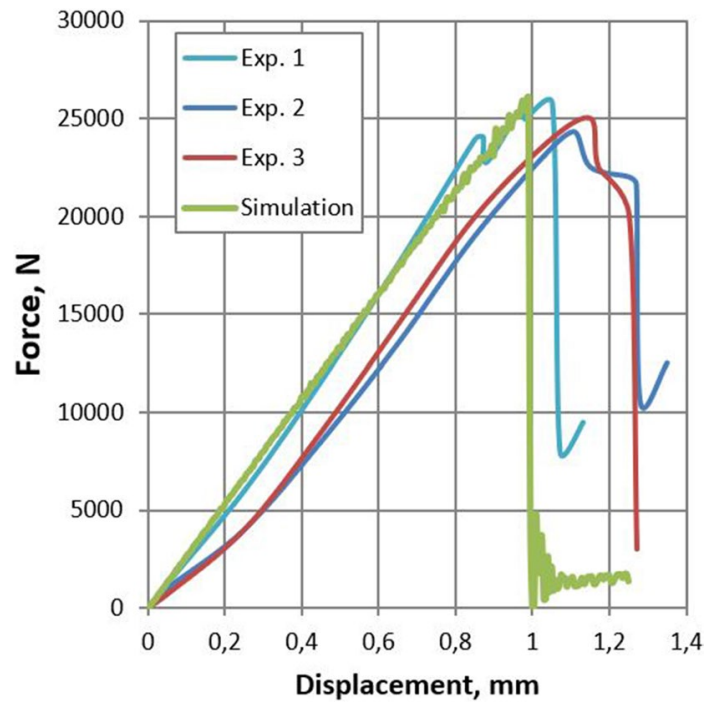

Fig. 7 Results of experimental and simulation UCS tests for concrete

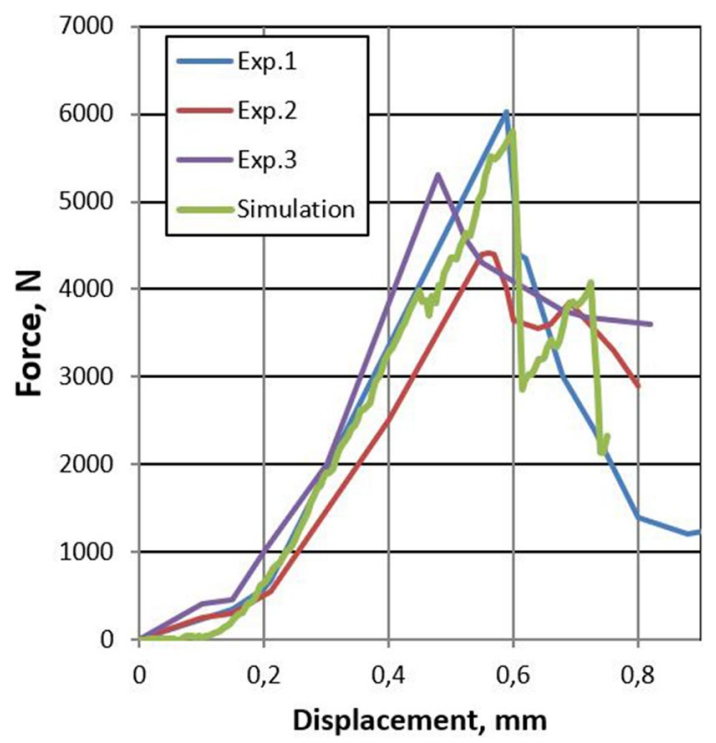

Fig. 8 Results of experimental and simulation BTS tests for concrete

verify the adequacy of the model. Figure 16 shows selected force waveforms for various configurations of process parameters and physical properties of rock samples for disc tools 150 and $160 \mathrm{~mm}(t=15 \mathrm{~mm})$. The recorded waveforms are characterised by the variability typical for the processes of rock centre destruction by a tool similar in profile to the wedge. Based on the simulation results (for both rock samples), it can be concluded that increasing the cut spacing from 15 to $25 \mathrm{~mm}$ causes an almost twofold increase in the pressing force. Increasing the disc diameter from 150
Table 2 The macro- and micro-properties of the DEM rock samples after calibration process

\begin{tabular}{lll}
\hline Parameter & Concrete & Sandstone \\
\hline Uniaxial compressive strength (UCS), MPa & 22.9 & 73 \\
Brazilian tensile strength (BTS), MPa & 2.7 & 6.4 \\
Young's modulus, GPa & 1.69 & 9.32 \\
Poisson's ratio & 0.28 & 0.18 \\
Radius of particles ( $\mathrm{R}_{\mathrm{DES}}$ ), mm & $1-2$ & 1 \\
Ratio shear to normal stiffness (PBS) & 0.4 & 0.4 \\
Parallel-bond normal stiffness (PBN), GPa & 1.3 & 9 \\
Bond normal stress limit $(\mathrm{PBN} S \mathrm{~S}), \mathrm{MPa}$ & 14 & 46 \\
Bond shear stress limit $(\mathrm{PBS} S \mathrm{~S}), \mathrm{MPa}$ & 14 & 46 \\
Normal spring constant $\left(\mathrm{K}_{\mathrm{n}}\right), \mathrm{KN} / \mathrm{mm}$ & 0.16 & 0.52 \\
Tangential spring constant $\left(\mathrm{K}_{\mathrm{s}}\right), \mathrm{KN} / \mathrm{mm}$ & 0.05 & 0.15 \\
MAXGAP, mm & -1 & -0.6 \\
SFA & 1.2 & 1.2 \\
Numerical damping coefficient $(\mathrm{ALPHA}), 0-1$ & 0.05 & 0.05 \\
Damping constant $\left(\mathrm{D}_{\mathrm{n}}\right), \mathrm{KN} \cdot \mathrm{ms} / \mathrm{mm}$ & 0.0023 & 0.0023 \\
\hline
\end{tabular}
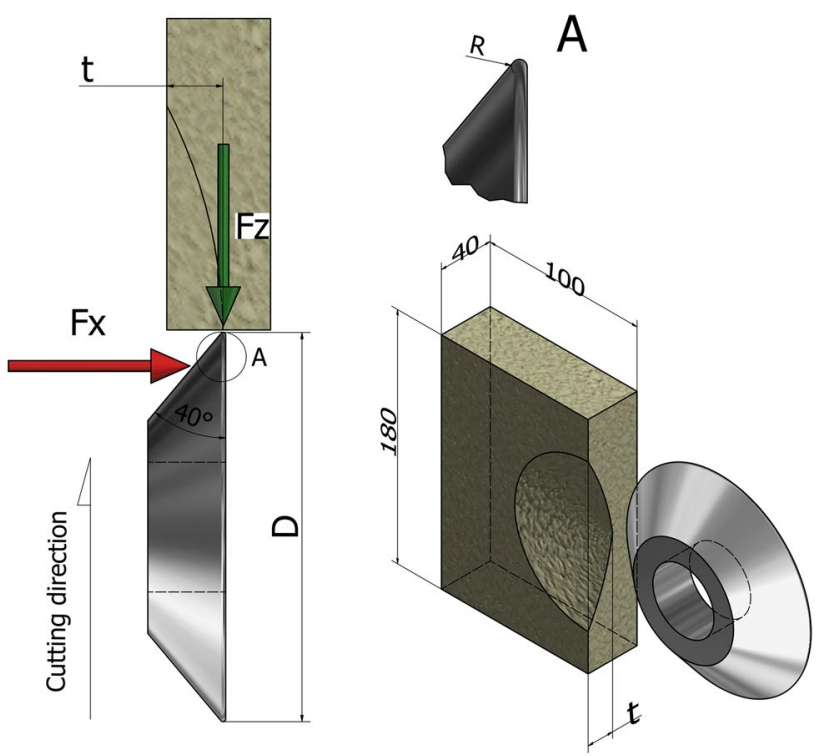

Fig. 9 Geometrical parameters of the rock-tool model (unit: $\mathrm{mm}$ )

to $160 \mathrm{~mm}$ resulted in an increase in the pressing force by about $15 \%$. The lateral force is approximately $35 \%$ of the normal force. Finally, the results of the simulation tests were used to identify the maximum destructive forces. In the next stage, these data were used to validate the numerical model.

\subsection{Validation of Numerical Model}

The purpose of experimental validation tests was to assess the accuracy of calculations using a numerical model. Laboratory research has been conducted in an analogy way to the 


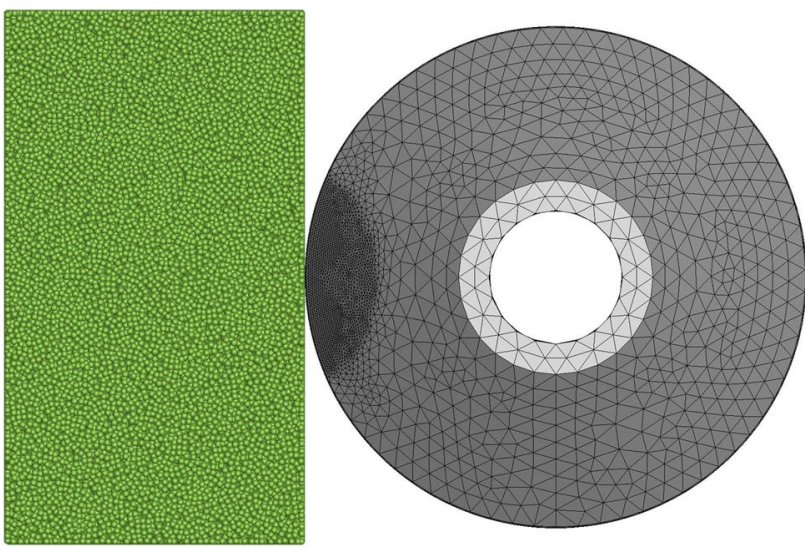

Fig. 10 Discretization of the rock-tool model in LS-Dyna

Table 3 Characterisation of the particle assembly for simulation tests with disc tools

\begin{tabular}{lll}
\hline Parameter & Concrete & Sandstone \\
\hline Radius of particles $\left(\mathrm{R}_{\mathrm{DES}}\right), \mathrm{mm}$ & $1-2$ & 1 \\
Number of particles & 17,615 & 57,316 \\
Coordination number $\left(\mathrm{n}_{\mathrm{c}}\right)$ & 8.94 & 10.01 \\
\hline
\end{tabular}

Fig. 11 Boundary conditions applied on the rock's model

therical one. Therefore, in laboratory tests, a disc tool with a diameter of 150 and $160 \mathrm{~mm}$ was tested, as well as rock samples with mechanical properties presented in Table 1. Experimental tests were carried out on a dedicated laboratory stand (Fig. 16). Each operation on the stand is carried out using hydraulic cylinders. The presented stand allows attaching the disc tool to the holder. The construction of this holder permits to change the position of the disc relative to the sample, and thus gives the opportunity to set the right cut spacing. The system is equipped with a strain gauge force sensor that allows measuring the pressure force in the range of 0-200 kN and a transformer displacement sensor with a measuring range of $0-300 \mathrm{~mm}$. The disc tool is pressed through the feed system of the station into a rock sample with a constant velocity. During the conducted research, the normal force $\left(\mathrm{F}_{\mathrm{z}}\right)$ and displacement of the disc tool were measured and recorded. Figure 17 shows exemplary forms of destruction of sandstone samples mined with disc tools $150 \mathrm{~mm}$ in diameter. On the right side of the figure, the form of a sample crack is presented after the analogous test has been performed on the simulation model. In contrast, Fig. 18 presents a form of spoil being the result of mining disc with diameters $\emptyset 160$ and the cut spacing $t=15 \mathrm{~mm}$. The analysis of the dimensions and form of rock fragments after mining tests showed that the numerical model predictions were reasonably accurate. Examples of normal force waveforms from experimental tests and simulations are shown in Figs. 19, 20, 21 and 22.

Quantitative results of laboratory and simulation tests are shown in Figs. 23, 24, 25 and 26. The graphs show the maximum (destructive) values of normal force. The blue colour in the graphs indicates the maximum normal force as an average of 5 experimental tests. The bars showing the simulation results are marked in red. The results of experimental and simulation tests for concrete samples are presented in Figs. 18 and 19. The results of tests for sandstone samples are shown in Figs. 20 and 21.

The agreement between simulation and measurement tests was assessed with relative errors (Table 4). The presented comparison shows that the model developed in LSDyna shows good accordance with the experimental studies. The discrepancy between the results of simulation tests is slightly larger for concrete samples. This is mainly due to the greater dispersion of the mechanical properties of concrete. The correlation between simulation and experimental tests for sandstone samples is very good. The maximum difference does not exceed $10 \%$ at all.

\subsection{Practical Use of Research Results}

The results presented in this paper show a great potential of DEM modelling in the aspect of load analysis of asymmetric disc tools. The rock-chipping process using asymmetric disc tools can be modelled with satisfactory accuracy at relatively high DEM particle radiuses. The test results confirm the possibility of scaling the models and increasing their complexity. Regardless of the above, the test results presented in 
Fig. 12 Simulation of concrete cutting $(D=150 \mathrm{~mm}$, $t=15 \mathrm{~mm})$-material damage
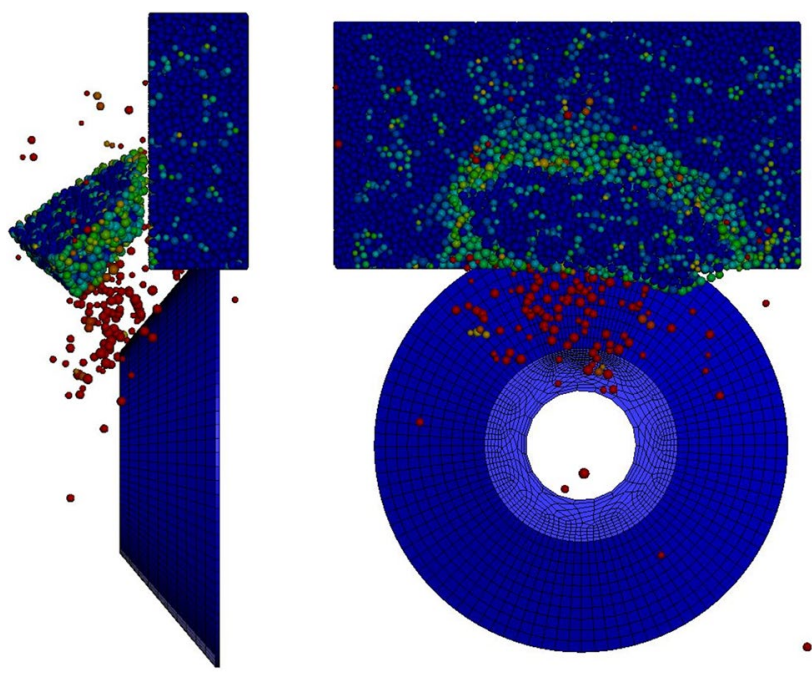

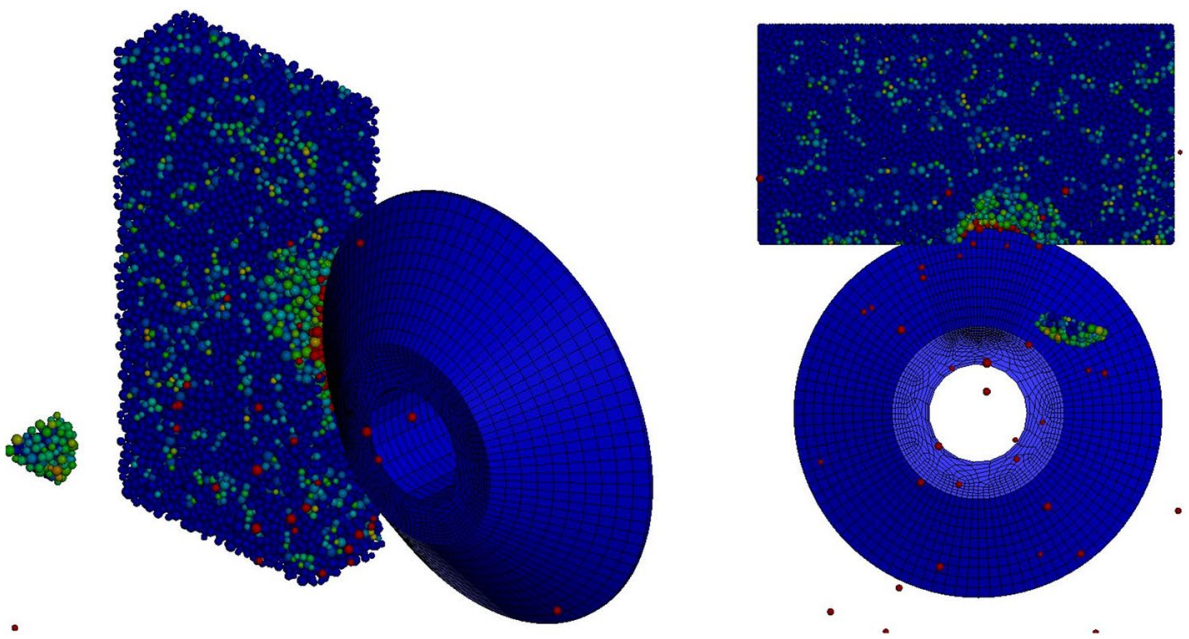

Fig. 13 Simulation of concrete cutting ( $D=150 \mathrm{~mm}, t=25 \mathrm{~mm})-$ material damage

Fig. 14 Simulation of sandstone cutting $(D=150 \mathrm{~mm}$, $t=15 \mathrm{~mm}$ )-material damage the paper can be used for approximate identification of work system loads in rock excavation performed by real machines. An example of this is the disc head design, which was constructed at the AGH University of Science and Technology in Cracow. The disc tools of this head move along a complex trajectory. However, the method of rock destruction is similar to the model of pressing a disc into a rock sample presented in this paper. This is due to the kinematics of working head system. Therefore, the approach presented in the paper was used to calculate the structural nodes of the disc head. A number of laboratory and field tests showed the correctness of adopted design assumptions. Figure 27 presents the disc test on a dedicated test stand. Whilst Fig. 28 shows a view of the disc head during the field tests.
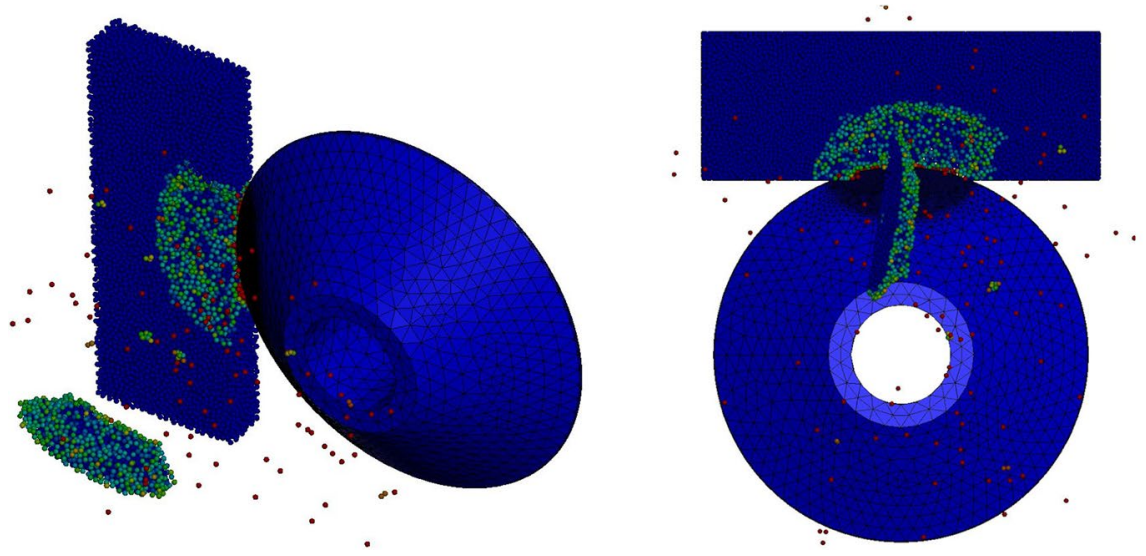
Fig. 15 Simulation of sandstone cutting $(D=160 \mathrm{~mm}$, $t=15 \mathrm{~mm})$-material damage

Fig. 16 Normal and lateral force histories for concrete (left) and for sandstone (right)
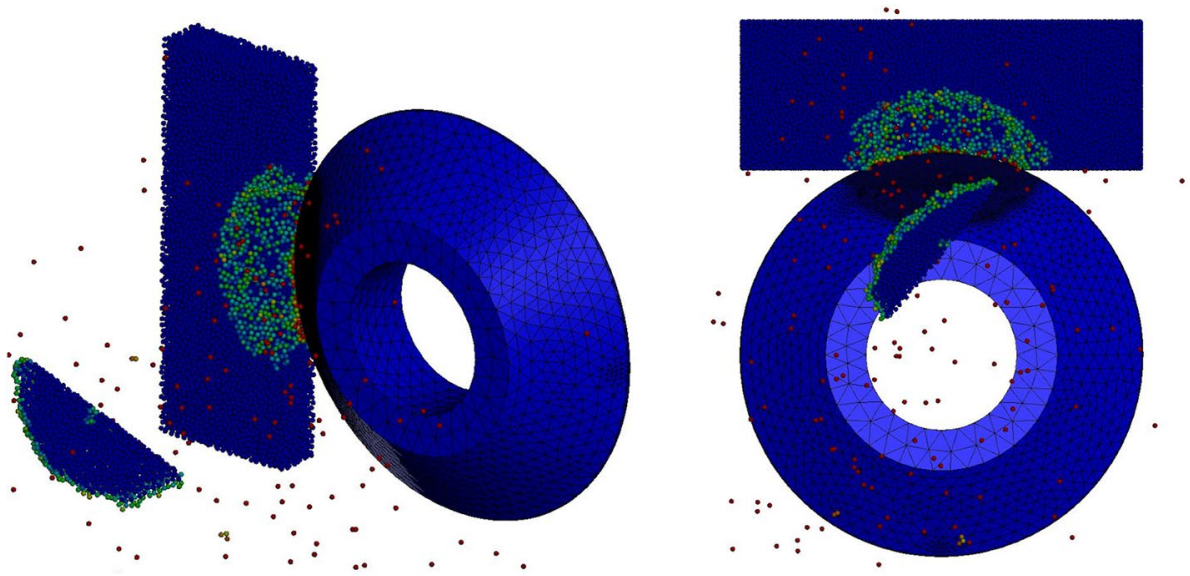

Sandstone
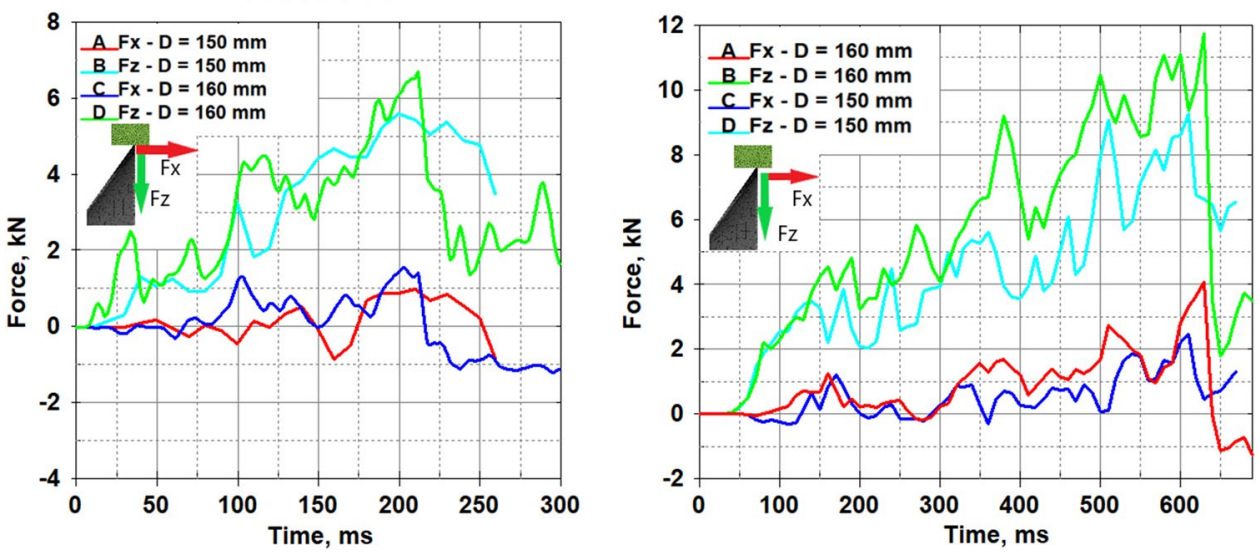

Fig. 17 The cracks in the front surface of the rock sample after mining tests (left) and the chip formation in numerical simulation (right)
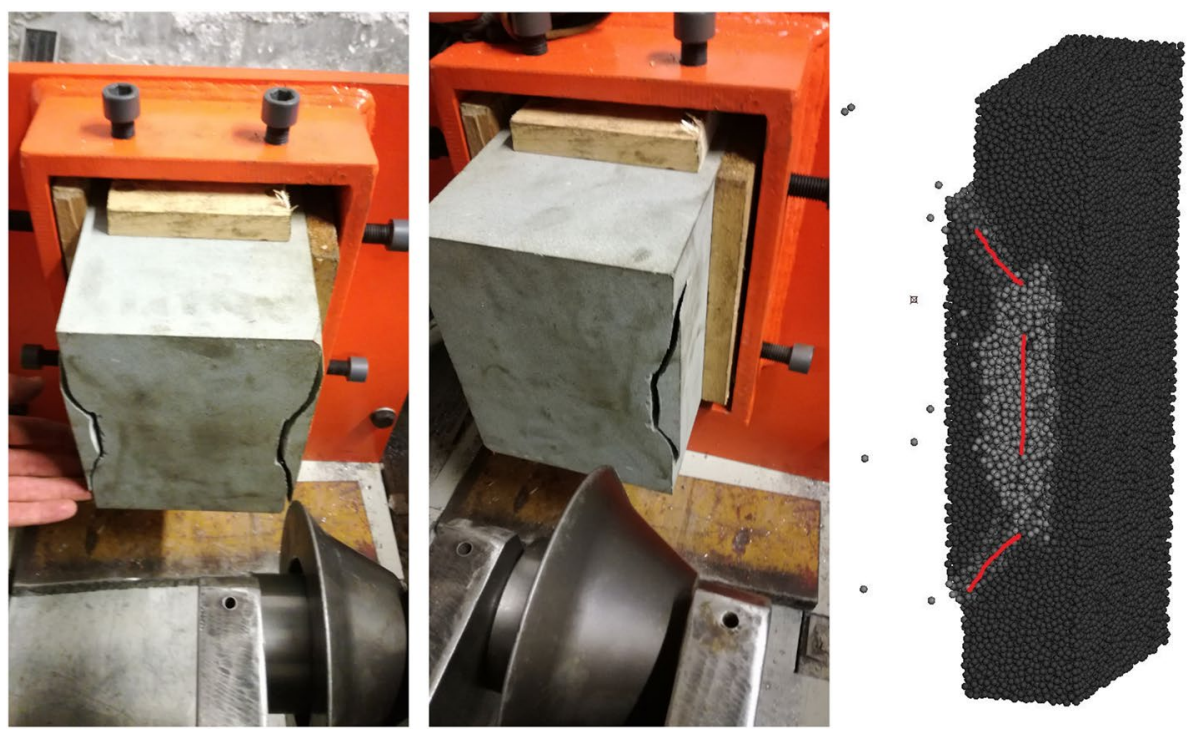
Fig. 18 Destruction zone dimensions (chip dimensions) after experimental (left) and simulation tests (right) - sandstone, $D=160, t=15 \mathrm{~mm}$
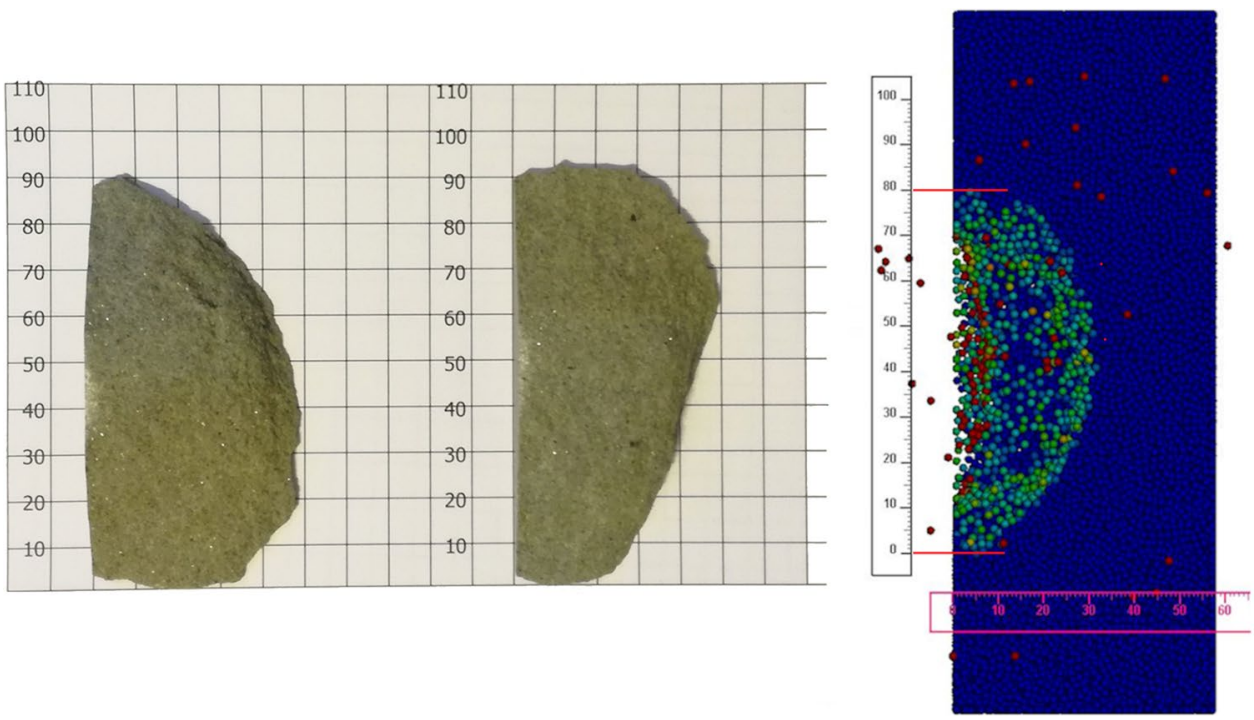

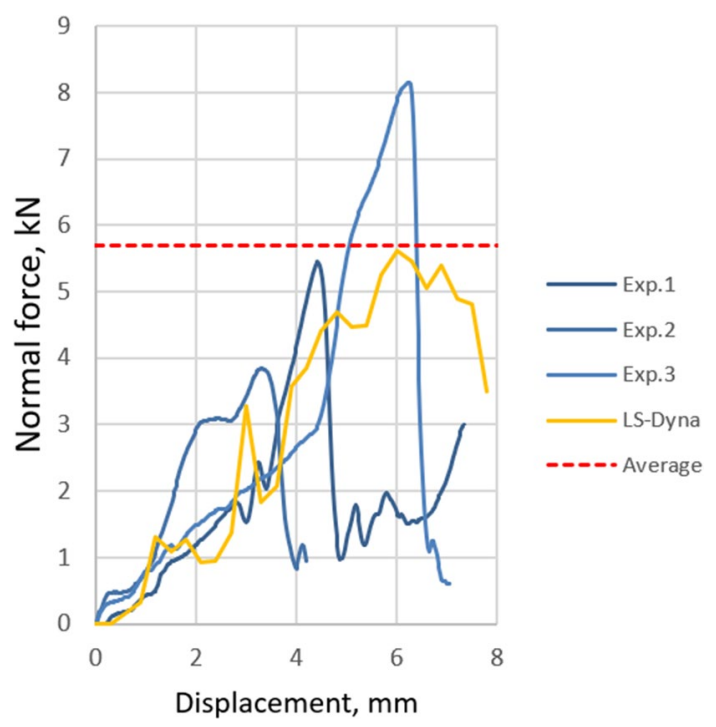

Fig. 19 Normal force-displacement curve for concrete $(D=150 \mathrm{~mm}$, $t=15 \mathrm{~mm}$ )

\section{Conclusion}

One of the fundamental problems of the application of asymmetrical disc tools in mining machine heads is the issues of identification of their loads. Currently, there are no model foundations that would allow evaluating a load of disc tools, especially in the conditions of complex mining kinematics. The development of computer simulation tools gives hope for the development of efficient mining models due to the required accuracy and acceptable time-consumption of each

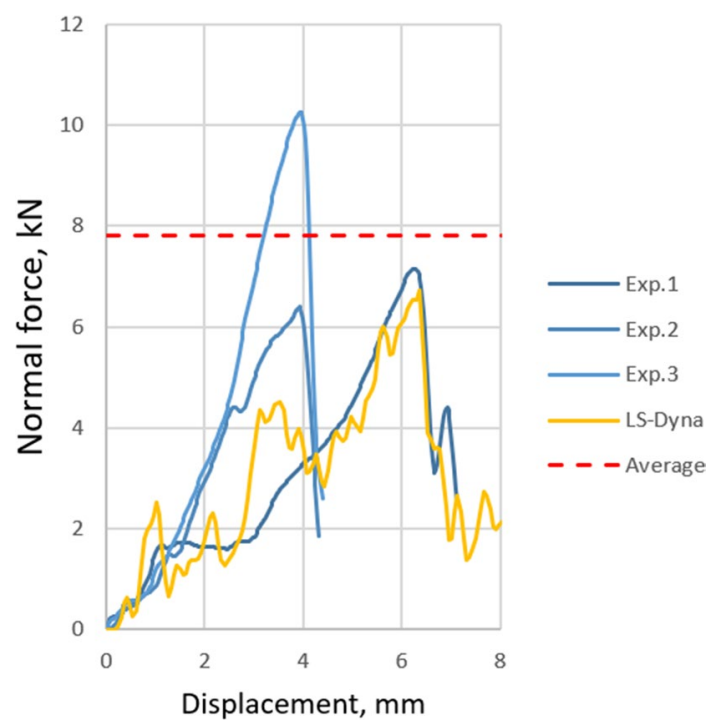

Fig. 20 Normal force-displacement curve for concrete $(D=160 \mathrm{~mm}$, $t=15 \mathrm{~mm})$

test. The use of advanced numerical models DEM will enable the expansion of research possibilities in this field.

The results of the model tests presented in the article show great possibilities in the field of rock destruction modelling, especially in the aspect of cutting rock with asymmetrical disc tools. Taking into account the above the simulation results, it should be emphasised that tested models are promising in terms of a balance between the speed of calculations and the accuracy of the simulation. An important result of the research was the identification of the particle size of the 


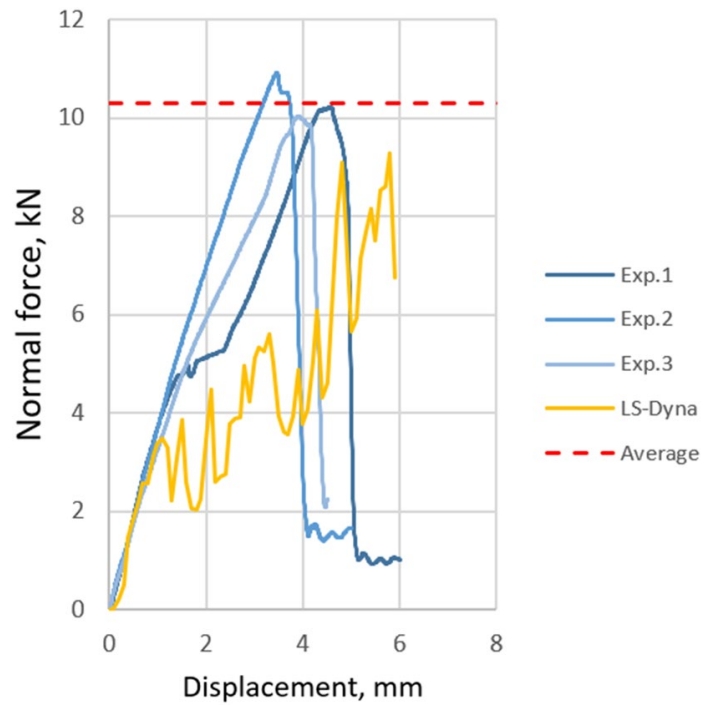

Fig. 21 Normal force-displacement curve for sandstone $(D=150 \mathrm{~mm}, t=15 \mathrm{~mm})$

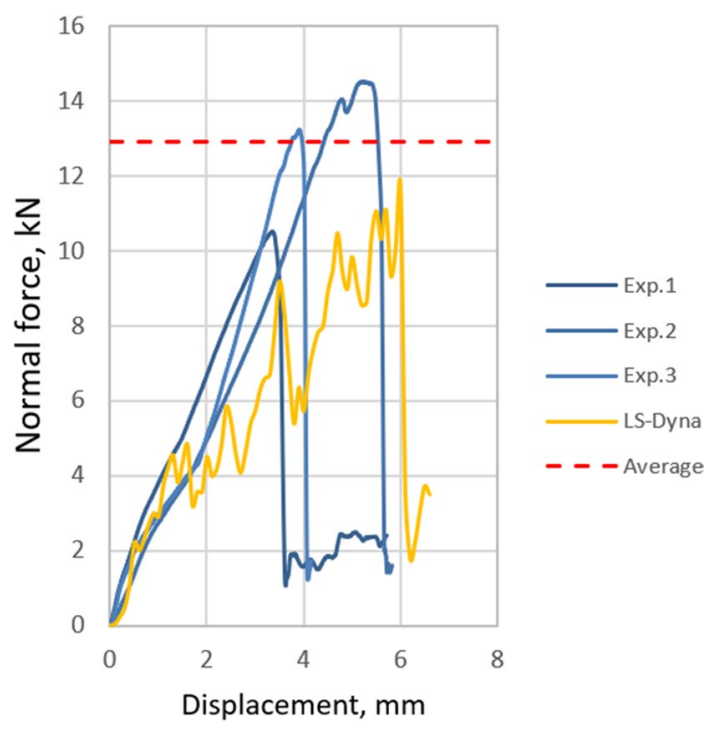

Fig. 22 Normal force-displacement curve for sandstone $(D=160 \mathrm{~mm}, t=15 \mathrm{~mm})$

numerical model (RDES) for which a good correlation with the experimental results was obtained. From a practical point of view, the presented test results can be input data for developing simulation models on a larger scale. Thus, it will be possible to take into account the complex kinematics of the dynamics of the rock-mining process with disc tools using the DEM simulation. Consequently, numerical modelling will be used instead of more expensive and time-consuming experimental works.

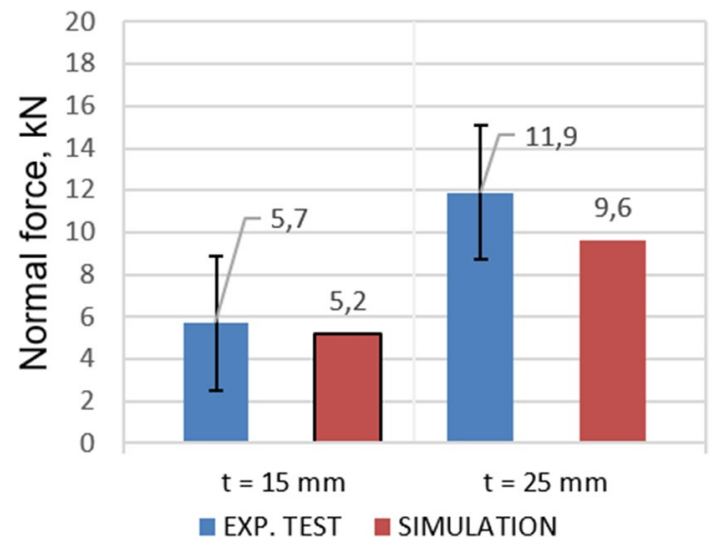

Fig. 23 Comparison of maximum normal force obtained in experiment and numerical simulation: concrete, $D=150 \mathrm{~mm}$

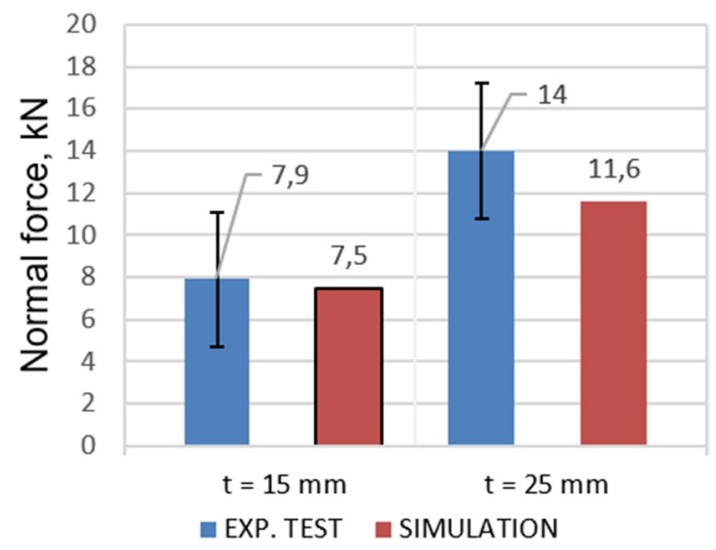

Fig. 24 Comparison of maximum normal force obtained in experiment and numerical simulation: concrete, $D=160 \mathrm{~mm}$

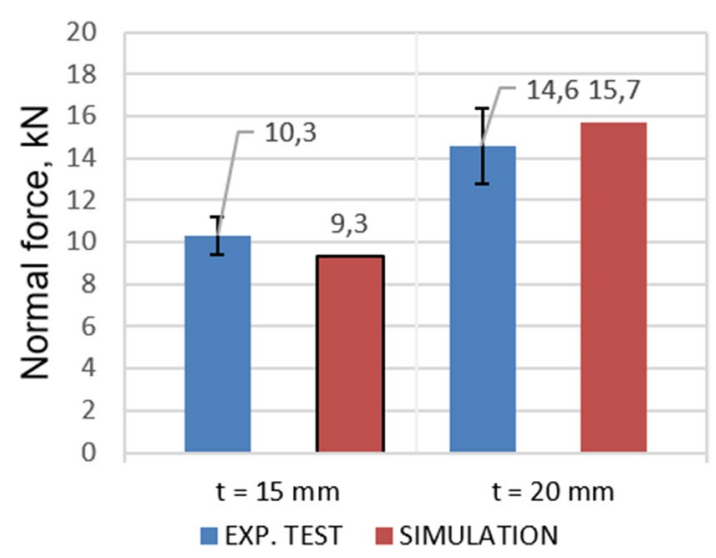

Fig. 25 Comparison of maximum normal force obtained in experiment and numerical simulation: sandstone, $D=150 \mathrm{~mm}$ 


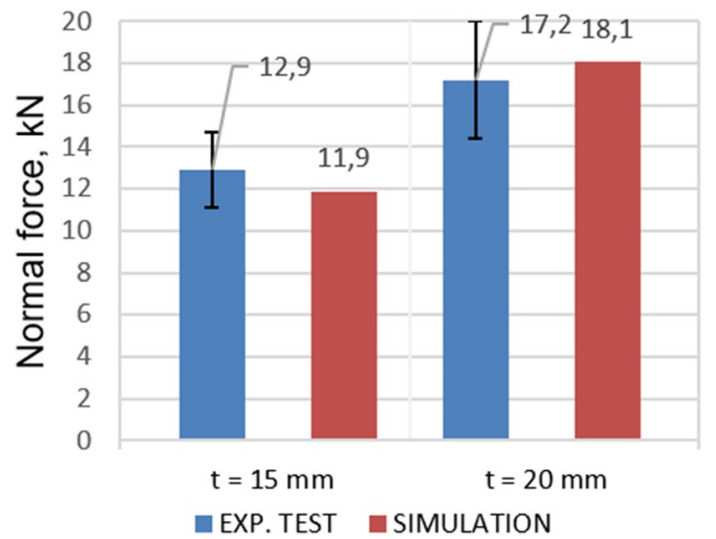

Fig. 26 Comparison of maximum normal force obtained in experiment and numerical simulation: sandstone, $D=160 \mathrm{~mm}$

Table 4 Relative errors between simulation and experimental tests

\begin{tabular}{lll}
\hline Disc diameter, cut spacing & \multicolumn{2}{l}{ Relative error (\%) } \\
\cline { 2 - 3 } & Concrete & Sandstone \\
\hline$D=150 \mathrm{~mm}, t=15 \mathrm{~mm}$ & 8.8 & 9.7 \\
$D=150 \mathrm{~mm}, t=20 \mathrm{~mm}$ & - & 7.5 \\
$D=150 \mathrm{~mm}, t=25 \mathrm{~mm}$ & 19.3 & - \\
$D=160 \mathrm{~mm}, t=15 \mathrm{~mm}$ & 5 & 8.5 \\
$D=160 \mathrm{~mm}, t=20 \mathrm{~mm}$ & - & 5.2 \\
$D=160 \mathrm{~mm}, t=25 \mathrm{~mm}$ & 17.1 & - \\
\hline
\end{tabular}

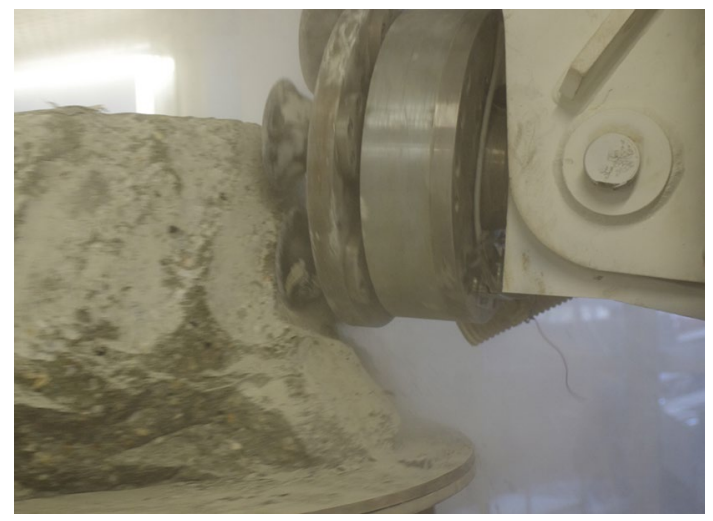

Fig. 27 Laboratory tests with the single disc plate

Open Access This article is licensed under a Creative Commons Attribution 4.0 International License, which permits use, sharing, adaptation, distribution and reproduction in any medium or format, as long as you give appropriate credit to the original author(s) and the source, provide a link to the Creative Commons licence, and indicate if changes were made. The images or other third party material in this article are included in the article's Creative Commons licence, unless indicated otherwise in a credit line to the material. If material is not included in the article's Creative Commons licence and your intended use is not

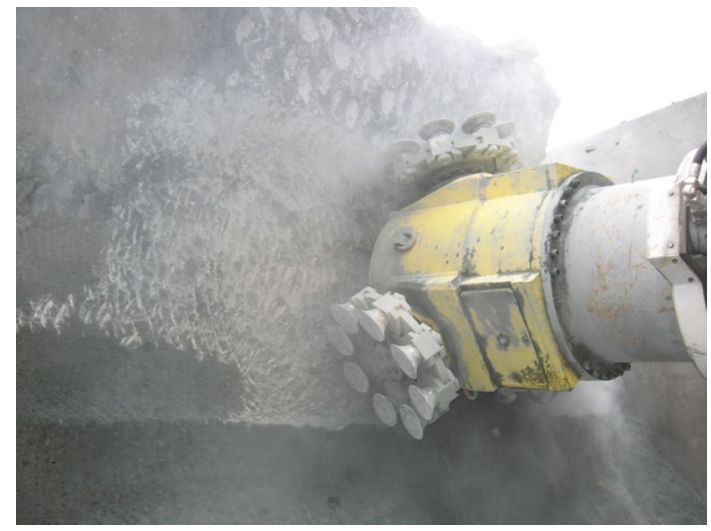

Fig. 28 The new generation mining head with disc tools during field tests

permitted by statutory regulation or exceeds the permitted use, you will need to obtain permission directly from the copyright holder. To view a copy of this licence, visit http://creativecommons.org/licenses/by/4.0/.

\section{References}

Acaroglu O, Erdogan C (2017) Stability analysis of roadheaders with mini-disc. Tunn Undergr Space Technol 68:187-195

Asbury B, Ozdemir L, Rostami J (1998) Mini disc equipped technology for hard rock minig, SME, Orlando, USA

Bołoz Ł, Leonel F, Castañeda, (2018) Computer-aided support for the rapid creation of parametric models of milling units for longwall shearers. Manag Syst Prod Eng 26(4):193-199

Cundall PA, Strack OD (1979) A discrete numerical model for granular assemblies. Geotechnique 29:47-65. https://doi.org/10.1680/geot. 1979.29.1.47

Flores-Johnson EA, Wang S, Maggi F et al (2016) Discrete element simulation of dynamic behaviour of partially saturated sand. Int J Mech Mater Des 12:495-507. https://doi.org/10.1007/ s10999-016-9350-5

Gospodarczyk P, Kotwica K, Stopka G (2013) A new generation mining head with disc tool of complex trajectory. Arch Min Sci 58(4):985-1006

Gospodarczyk P, Kotwica K, Mendyka P, Stopka G (2016) Innovative roadheader mining head with asymmetrical disc tools, exploration and mining, mineral processing. Int Multidiscip Sci GeoConf SGEM 2:489-496

Hallquist JO (2015) LS-DYNA keyword user's manual, Version R8.0. Livermore Software Technology Corporation, California

Jaime MC, Zhou Y, Lin J-S, Gamwo I (2015) Finite element modeling of rock cutting and its fragmentation process. Int J Rock Mech Min Sci 80:137-146

Jeong H, Choi S, Jeon S (2019) Current status of rock cutting technique using undercutting concept. Tunn Undergr Space 29(3):148-156. https://doi.org/10.7474/TUS.2019.29.3.148

Karajan N, Lisner E, Han Z, Teng H, Wang J (2012) Particles as discrete elements in LS-DYNA: interaction with themselves as well as deformable or rigid structures. In: 11th LS-DYNA Forum, Ulm

Kotwica K (2018) Atypical and innovative tool, holder and mining head designed for roadheaders used to tunnel and gallery drilling 
in hard rock. Tunn Undergr Space Technol 82:493-503. https:// doi.org/10.1016/j.tust.2018.08.017

Labra C, Rojek J, Oñate E (2017) Discrete/finite element modelling of rock cutting with a TBM disc cutter. Rock Mech Rock Eng 50(3):621-638

Li H, Du E (2016) Simulation of rock fragmentation induced by a tunnel boring machine disk cutter. Adv Mech Eng 8(6):1-11

Li X, Huang B, Li C, Jiang S (2012a) Dynamics analysis on roadheader cutting head based on LS-DYNA. J Converg Inform Technol 7(2012):333-340

Li X, Du W, Huang Z, Fu W (2012b) Simulation of disc cutter loads based on ANSYS/LS-DYNA. Appl Mech Mater 127(2012):385-389

Qianqian Z, Zhennan H, Mengqi Z, Jianguang Z (2015) Prediction of tool forces in rock cutting using discrete element method. Electron J Geotech Eng 20:1607-1625

Ramezanzadeh A, Hood M (2010) A state-of-the-art review of mechanical rock excavation technologies. Int J Min Environ Issues. 1(1)

Rojek J (2007) Discrete element modeling of rock cutting. Comp Method Mater Sci 7:224-230

Rojek J, Onate E, Labra C, Kargl H (2011) Discrete element simulation of rock cutting. Int J Rock Mech Min Sci 48(6):996-1010

Stopka G. (2019). Numerical simulation in design process of the new generation mining head with disc tools. Systemy Wspomagania w Inżynierii Produkcji: ISSN 2391-9361-2019. Górnictwo-perspektywy i zagrożenia. 8(1): 164-172

Stopka G (2020) Laboratory research on the influence of selected technological parameters on cutting forces during hard rock mining with asymmetric disc tools. Acta Montanistica Slovaca. 25(1): 94-10. https://doi.org/10.46544/AMS.v25i1.9

Takeda S, Ogawa K, Tanigaki K et al (2018) DEM/FEM simulation for impact response of binary granular target and projectile. Eur Phys J Spec Top 227:73-83. https://doi.org/10.1140/epjst/ e2018-00071-3

Ten H, Wang J, Karajan N, Han Z (2013) Interaction possibilities of bonded and looseparticles in ls-dyna. DYNAmore GmbH, Livermore Software Technology Corp., 9th European LS-DYNA Conference

Weber W (1995) Driving different cross-sections using undercutting technology-the development of a new type of cutting machine. Tunnels and Tunneling, Baum; special issue; 74-80

Xia YM, Guo B, Cong GQ, Zeng GY (2017) Numerical simulation of rock fragmentation induced by a single TBM disc cutter close to a side free surface. Int J Rock Mech Min Sci 91:40-48

Zárate F, Oñate E (2015) A simple FEM-DEM technique for fracture prediction in materials and structures. Comp Part Mech 2:301314. https://doi.org/10.1007/s40571-015-0067-2

Zhang G, Dang W, Herbst M, Song Z (2020) Complex analysis of rock cutting with consideration of rock-tool interaction using distinct element method (DEM). Geomech Eng 20(5):2020

Publisher's Note Springer Nature remains neutral with regard to jurisdictional claims in published maps and institutional affiliations. 